production of immunity or in healing the disease is the time which elapses between the infection and the protective inoculation, that the action of the latter is the more rapid and the more successful the sooner it follows upon the former, it is at once apparent where, at any rate, some of the difficulties lie in its successful application to human beings. Whereas the exact moment is known when the experimental infection in the animal takes place, in the human subject days or weeks may pass between the infection and the declaration of the disease.

\section{THE CENTENARY OF GILBERT WHITE.}

THE wonted tranquillity of the little Hampshire village of Selborne was disturbed on Saturday by the invasion of a band of pilgrims who came to look upon the shrine of Gilbert White, and by the sight obtained a renewed love of nature. Drawn by a feeling of regard, members of the Selborne Society, and other disciples of White, congregated from all parts of the country, and paid homage to their master. Never within the memory of the oldest inhabitant had so many people been gathered together at Selborne, and we doubt not that the villagers failed to realise what attraction there could be in a man whose characteristics, according to an old woman who remembered him, were that "he would walk about the lanes tap-tapping at the trees, and stooping every now and then to wipe the dust off his shoes." But one thing marred the enjoyment of Saturday's meeting. A band of gipsies, with a terrible barrel-organ, and all the paraphernalia of a country fair, had installed themselves not a stone's-throw from the house in which Gilbert White lived his peaceful life. And, worst of all, they possessed a steam-syren, the shriek and screech of which penetrated everywhere, even to the high Hangers, in which the Selborne naturalist supposed that swallows hibernated.

The Earl of Selborne presided at luncheon, and, in propos ing "The Memory of Gilbert White," dwelt upon the sterling qualities of the man, and the remarkable character of his books dealing with the natural history and antiquities of Selborne. White's life was devoted to ohserving and recording natural productions and phenomena. $\mathrm{He}$ was gifted with shrewdness of discenment, and that one essential qualification of a true man of science-the power of faithfully chronicling all and every observation. It was thought by some that the naturalist whose centenary they were commemorating had nothing else to do but wander about, and observe the habits of birds, beasts, fishes, and insects; but that was a great mistake. He had to perform "the daily round, the common task" that falls to the lot of all, and diligently did he fulfil his duties.

Mr. Darwin proposed "Prosperity to the Selborne Society and its branches." In responding, Mr. Otter, one of the founders of the society, dwelt upon the fact that their object was to inculcate and foster a love of nature, and to wage war in defence of her beauties. To them the rutbless field-naturalist and the sporting collector of specimens were enemies.

Mr. Wakefield followed with a description of the good work done by the Thames Valley branch in preserving "beautyspots" from jerry-builders and their kindred.

The Earl of Stamford, in proposing "Prosperity to the Hampshire Field Club," the members of which joined the London party at Selborne, remarked that be had found reason to believe that one of the figures shown in the quarto edition of White's book is a likeness of the author himself, hence it could no longer be said that no portrait of him was in existence. Mr. R. H. White, however, was of the opinion that the evidence was not of a positive character.

The question of a memorial to White was touched by the Earl of Selborne, but he thought that the best plan would be to "Look not on the picture, but the book," and leave that to be handed down to the end of time, for nothing more was needed to perpetuate the memory of the man. With this sentiment we by no means agree. A monument is not erected merely to prevent a man's name and deeds from sinking to oblivion. It should show to the people that he was one whom $m \in n$ delight to honour. We are apt to be far too prosaic in these matters, and to consider the raising of images and other memorials as more or less unnecessary conventionalities. This conviction has grown upon us because we have seen statues erected to comparatively obscure individuals time without number, while the works of men of science are unrecognised. It does not say much for the naturalists of this country if the centenary of Gilbert White is allowed to pass without some tangible illustration being given of their regard for the father of them all.

\section{INTERFERENCE BANDS AND THEIR APPLICATIONS. ${ }^{1}$}

THE formation of the interference bands, known as Newton's rings, when two slightly curved glass plates are pressed into contact, was illustrated by an acoustical analogue. A high pressure flame B (Fig. I) is sensitive to sounds which reach it in the direction EB, but is insensitive to similar sounds which reach it in the nearly perpendicular direction AB. A is a "birdcall," giving a pure sound (inaudible) of wave-length $(\lambda)$ equal to about $\mathrm{I} \mathrm{cm}$. ; C and D are reflectors of perforated zinc. If $\mathrm{C}$ acts alone, the flame is visibly excited by the waves reflected from it, though by far the greater part of the energy is trans. mitted. If $\mathrm{D}$, held parallel to $\mathrm{C}$, be then brought into action, the result depends upon the interval between the two partial reflectors. The reflected sounds may co-operate, in which case the flame flares vigorously; or they may interfere, so that the flame recovers, and behaves as if no sonnd at all were falling upon it. The first effect occurs $w$ hen the reflectors are close together, or are separated by any multiple of $\frac{1}{2} \sqrt{ } 2 . \lambda$; the

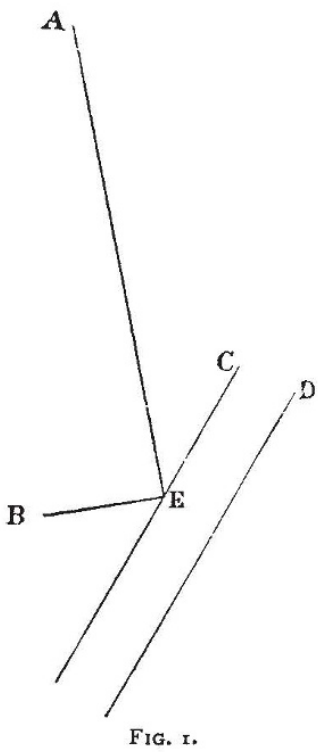

second when the interval is midway between those of the abovementioned series, that is, when it coincides with an odd multiple of $\frac{1}{4} \sqrt{2} \lambda$. The factor $\sqrt{ } 2$ depends upon the obliquity of the reflection.

The coloured rings, as usually formed between glass plates, luse a good deal of their richness by contamination with white light reflected from the exterior surfaces. The reflection from the hindermost surface is easily got rid of by employing an opaque glass, but the reflection from the first surface is less easy to deal with. One plan, used in the lecture, depends upon the use of slightly wedge-shaped glasses $\left(2^{\circ}\right)$ so combined that the exterior surfaces are parallel to one another, but inclined to the interior operative surfaces. In this arrangement the false light is thrown somewhat to one side, and can be stopped by a screen suitably held at the place where the image of the electric arc is formed.

The formation of colour and the ultimate disappearance of the bands as the interval between the surfaces increases, depends upon the mixed character of white light. For each colour the bands are upon a scale proportional to the wave-length for that colour. If we wish to observe the bands when the interval is

${ }^{1}$ Abstract of a lecture delivered at the Royal Institution, on Friday, March 24, 1893, by Lord Rayleigh.

NO. [ 235 , vOL. 48] 